\title{
Comparative Examination between the Perceived Inventory of Technological Competency as Caring in Nursing (PITCCN) and the Technological Competency as Caring in Nursing Instrument (TCCNI)
} Mie Miyamoto ${ }^{1}$, Misao Miyagawa ${ }^{2}$, Tetsuya Tanioka ${ }^{3 *}$, Yuko Yasuhara ${ }^{3}$, Rozzano Locsin $^{3}, K_{y o k o}$ Osaka $^{3}$, Hirokazu Ito ${ }^{3}$ and Waraporn Kongsuwan ${ }^{4}$

${ }^{1}$ Department of Nursing, Tokushima Prefectural Central Hospital, Tokushima, Japan

${ }^{2}$ Department of Nursing, Faculty of Health and Welfare, Tokushima Bunri University, Tokushima, Japan

${ }^{3}$ Department of Nursing, Institute of Biomedical Sciences, Tokushima University Graduate School, Tokushima, Japan

${ }^{4}$ Department of Adult and Elderly Nursing, Faculty of Nursing, Prince of Songkla University, Songkhla, Thailand

\begin{abstract}
Background: Technological Competency as Caring in Nursing Instrument (TCCNI) was developed by Rozzano Locsin (2013) to determine the expression of "technological competency" as caring in nursing among practicing nurses. While the TCCNI was translated into other languages, no instrument measuring the 'technological competency as caring in nursing' among Japanese nurses was developed and tested. Considering culture and social background influencing measurement of the phenomena, Kato et al. (2016) re-envisioned the TCCNI to focus on caring behaviors of nurses in acute care settings. The Perceived Inventory of Technological Competency of Caring in Nursing (PITCCN) was developed. Aim: The aim of this study is to perform comparative examination between the PITCCN and the TCCNI. Methods: The authors developed the Japanese version of the TCCNI from its original instrument subjecting this to reverse translation using a professional English-to-Japanese-to-English translator who clearly confirmed the accuracy of the translations. In this study, the contents of the item configurations were analyzed and discussed regarding instruments, and the summary of the similarities and differences among researchers who had been involved in the research of caring. The difference between the item configuration of PITCCN and TCCNI was clearly illustrated by a comparative table, and in the case where there was no corresponding item, it was left blank.

Results: The commonality between the TCCNI and PITCCN was the holistic focus on patients using information obtained through technologies. Different question items were included to provide highquality outcomes for the PITCCN.

Conclusion: Considered useful in order to perform high quality practice in using technology, and to provide high quality nursing. Measured Technological Competency as Caring in Nursing might be able to utilizing for in-service education of hospitals or formalized education in nursing universities.
\end{abstract}

Publication History:

\section{Aims and Objectives}

Since Mayeroff (1971) describe "caring" in his book [1], caring has attracted attention in the discipline of nursing as evidenced by various educational. Research, and practice engagements and expanding caring science perspectives.

The dynamic essence of nursing as caring, unfortunately, has led to different terms such as care, care-giving, care-receiving, care-cure, nursing care, etc. Oftentimes, these terms are used interchangeably which promotes confusion, thereby acknowledging the concept of care as one of the least understood aspects of nursing [2].

Care is a powerful and dynamic force towards understanding the totality of human behavior in health and illness. Action modes related to care which are culturally-based and maintained influence beneficial health outcomes. Care needs to be understood and actualized in diverse and specific cultural contexts [3]. Leininger [4] holds that culture is the broadest, most comprehensive, holistic and universal feature of human beings and care is predicted to be embedded in culture.

In Japan, Sato et al. [5] described the key words forming the core of caring as "self-actualization, self-development, mindfulness, empathy and human relationship." However, technological competency as caring in nursing presents the link between technology and caring in nursing as coexisting harmoniously in the moment (Locsin, 2005, p. 6). Caring is an important and indispensable concept [6] in nursing; however, it is also known as difficult for non-nurses to understand what its nature of being is [7]. Katsuhara [8] also declared that in the current situation, it is hard to understand what are nurse specialists, and their practice scope. Therefore, if the actions and thoughts such as those of caring expressions by nurses are visualized and measured, it may be quite easier for others to recognize, clarify, and realize expert nursing practice.

Watson [9] has provided the essential research tools for assessing and measuring caring for those in the nursing professions. These "Corresponding Author: Prof. Tetsuya Tanioka, Department of Nursing, Institute of Biomedical Sciences, Tokushima University Graduate School, Tokushima, Japan; E-mail: tanioka.tetsuya@tokushima-u.ac.jp

Citation: Miyamoto M, Miyagawa M, Tanioka T, Yasuhara Y, Locsin R, et al. (2017) Comparative Examination between the Perceived Inventory of Technological Competency as Caring in Nursing (PITCCN) and the Technological Competency as Caring in Nursing Instrument (TCCNI). Int J Nurs Clin Pract 4: 267. doi: https:// doi.org/10.15344/2394-4978/2017/267

Copyright: (c) 2017 Miyamoto et al. This is an open-access article distributed under the terms of the Creative Commons Attribution License, which permits unrestricted use, distribution, and reproduction in any medium, provided the original author and source are credited. 
Citation: Miyamoto M, Miyagawa M, Tanioka T, Yasuhara Y, Locsin R, et al. (2017) Comparative Examination between the Perceived Inventory of Technological Competency as Caring in Nursing (PITCCN) and the Technological Competency as Caring in Nursing Instrument (TCCNI). Int J Nurs Clin Pract 4: 267. doi: https://doi.org/10.15344/2394-4978/2017/267

Page 2 of 5

measurements address quality of care, patient, client, and nurse perceptions of caring, and caring behaviors, abilities, and its efficacy. Two of these instruments are the Caring Assessment Report Evaluation Q-sort (CARE-Q) [10], and the Caring Behaviors Inventory (CBI) [11] introduced as measurements for evaluating the recognition of nurses' caring behavior. In addition, although not published in this book, another instrument that measures caring in nursing, specifically the expression of technological competency as caring is Technological Competency as Caring in Nursing Instrument (TCCNI) [12-14]. Even with this recent instrument, none exists that relates to technological competency as caring in nursing considering the Japanese culture and social background. For this critical sociopolitically and culturally-based reason, Kato et al. [15] focused their attention on developing and testing technological caring behaviors of nurses in acute care nursing by using the Perceived Inventory of Technological Competency as Caring in Nursing (PITCCN) in the intensive care unit.

The purpose of this study was to compare the question items of the TCCNI with the PITCCN with the aim of developing a reliable instrument to measure Technological Competency as Caring in Nursing of nurses in Japan.

\section{Methods}

\section{The PITCCN and the TCCNI}

As the PITCCN was developed using the Japanese language, the authors translated it into English. The Cronbach's alpha of all items of the TCCNI outside of Japan was 0.81-0.87 [13]. Meanwhile, the Cronbach's alpha of all items of the PITCCN with 300 Japanese nurses responding was 0.89 indicating and confirming high internal consistency [15]. There are negatively worded items (Q12, Q13, Q14, Q15, and Q22) in the PITCCN, however the TCCNI did not have.

\section{Analysis method}

The authors developed the Japanese version of the TCCNI from its original instrument subjecting this to reverse translation using a professional English-to-Japanese-to-English translator who clearly confirmed the accuracy of the translations [16]. The contents of the item configurations were analyzed and discussed regarding instruments, and the summary of the similarities and differences among researchers who had been involved in the research of caring.

The difference between the item configuration of PITCCN and TCCNI was clearly illustrated by a comparativetable, and in the case where there was no corresponding item, it was left blank.

\section{Ethical Considerations}

This research study was approved by the Tokushima University Hospital Ethics Board (No. 2914). Furthermore, source of TCCNI [13] and PITCCN [15] were shown.

\section{Results}

Table 1 shows the results of comparing the 25 items of the TCCNI [13] and the 23 items of the PITCCN [15]. However, four of the 23 items of the PITCCN did not match with the TCCNI (Table 2).

\section{Discussion}

Although technology is not a new concept within nursing, Locsin (2001) has made it clear that technology and techniques are somewhat different, in that nurses have always used techniques and technologies as tools in meaningful ways to achieve valued ends.

The theory of Technological Competency as Caring in Nursing (TCCN) was developed in 1999 initially as a theoretical essay published in the Image: Journal of Nursing Scholarship. Subsequent theoretical developments were based on Boykin \& Schoenhofer's (2001) theory of Nursing as Caring from which assumptions structuring the TCCN was based, such as of persons' wholeness in the moment and of nursing as a discipline and a professional practice. The description of caring persons and the practice process of knowing persons as caring were founded on their theory as well. In Boykin \& Schoenhofer's theory, the nurse accepts the person cared for at face value "in the moment". Nursing activities are not directed at changing the patient to meet the goals set by the nurse, but rather towards understanding that the patient is unfolding while living the meaning of his or her own life.

The TCCNI [13] items were developed based on the following five assumptions: (1) Persons are caring by virtue of their humanness (Boykin \& Schohenhofer, 2001), (2) Persons are whole and complete in the moment (Boykin \& Schohenhofer, 2001), (3) Knowing person is a process of nursing (Locsin, 2005), (4) Technology is used to know the persons as whole in the moment (Locsin, 2005), and (5) Nursing is a discipline and a profession (Boykin \& Schoenhofer, 2001). In Locsin's theory nurses are expected to understand the patients whom they are caring for, and that caring should focus on how they dare to live their own lives fully at every moment with their dreams and hopes. As a basic idea of the TCCN, knowing persons as caring is appreciated as a process of nursing, and that humans are perfect and integrated beings at every moment. Nurses are expected to understand and support their patients and their families by making the best use of technology. Technology for medical treatment and nursing is an element of caring and that nurses who can make good use of technology are highly respected in their abilities of caring.

On the other hand, the PITCCN was developed based on Locsin's middle range theory of the TCCN [17]. The central concept of PITCCN was influenced by patterns of knowing in nursing as identified and described by Carper (1978). These are empirics, personal, ethics, and aesthetics [18]. In addition, PITCCN has assumed empirical knowing as a process to understand persons using technologies contributing to the scientific knowledge to support nursing interventions. The PITCCN is constituted four factors: (1)Training of nurses to provide optimal care, (2) Empirical knowledge and whole human knowing, (3) Utilization of information obtained from technology and continuous knowing, and (4) Intentional and ethical nursing of person.

TCCNI and PITCCN had many similar points particularly on knowing persons as caring. In the TCCNI, question No. 19 (Knowing patients involves respecting the person as whole and complete in each moment), it was considered that questions in the PITCCN numbers Q 8, 9, 12, 13, and 14 corresponded to it.

As for the process of knowing persons, Boykin \& Schoenhofer (2001) [19] stated, that "there is no lack, failure, or inadequacy, which is to be corrected through nursing.... Persons are whole, complete and caring in the moment" (p. 12). The act of caring between the nurse and the one nursed improves personhood and establishes the hopes, dreams, and aspirations towards living the meaning of one's own life. 
Citation: Miyamoto M, Miyagawa M, Tanioka T, Yasuhara Y, Locsin R, et al. (2017) Comparative Examination between the Perceived Inventory of Technological Competency as Caring in Nursing (PITCCN) and the Technological Competency as Caring in Nursing Instrument (TCCNI). Int J Nurs Clin Pract 4: 267. doi: https://doi.org/10.15344/2394-4978/2017/267

Page 3 of 5

\begin{tabular}{|c|c|c|c|}
\hline \multicolumn{2}{|r|}{ TCCNI } & \multicolumn{2}{|r|}{ PITCCN } \\
\hline 1 & Nursing, an important part of healthcare, focuses on human caring. & & \\
\hline \multirow[t]{2}{*}{2} & \multirow[t]{2}{*}{ Technology assists nurses in knowing the "who" and "what" of persons. } & Q1 & $\begin{array}{l}\text { Nurses assess patient's condition from information acquired using technology. } \\
\text { (Empirical knowing) }\end{array}$ \\
\hline & & Q2 & $\begin{array}{l}\text { Nurses understand the condition of their patients based on information } \\
\text { acquired from technology. (Empirical knowing) }\end{array}$ \\
\hline 3 & The outcome of nursing is healing - saving lives and increasing a sense of self. & & \\
\hline 4 & Nurses use unique techniques to care for patients. & Q18 & Nurses behave in ways to can gain the trust of patients. (Aesthetic knowing) \\
\hline \multirow[t]{2}{*}{5} & \multirow{2}{*}{$\begin{array}{l}\text { Caring is engaging in compassion, physical presence, comforting and } \\
\text { respecting the whole person. }\end{array}$} & Q11 & Nurses encourage patients by caring emotionally. \\
\hline & & Q15 & Nurses encourage patients by touching their body. \\
\hline 6 & Technology and caring help to build patient self-worth when used without bias. & & \\
\hline 7 & $\begin{array}{l}\text { Knowing the "what" and "who" about a patient means to appreciate the patient } \\
\text { as more than his/her physical parts. }\end{array}$ & Q10 & Nurses know the whole patient. (Personal knowing) \\
\hline 8 & Nursing is a unique field of knowledge, skills, and caring abilities. & & \\
\hline 9 & Caring in nursing is listening to, doing with, and being with the patient. & & \\
\hline 10 & $\begin{array}{l}\text { Nurses need to balance the demands of using machine technologies } \\
\text { competently with caring in nursing. }\end{array}$ & & \\
\hline 11 & $\begin{array}{l}\text { Caring means knowing the person's physical self and his/her emotional } \\
\text { conditions in a particular moment. }\end{array}$ & Q7 & Nurses empathize with what patients are experiencing. (Personal knowing) \\
\hline 12 & $\begin{array}{l}\text { Nurses must include patients in designing care plans to ensure accuracy and } \\
\text { completeness of their care. }\end{array}$ & & \\
\hline 13 & $\begin{array}{l}\text { Technological competence is the proficient use of machines within a caring } \\
\text { point of view. }\end{array}$ & & \\
\hline 14 & $\begin{array}{l}\text { Nurses must respect patients' personal hopes and dreams, which may change } \\
\text { from one moment to the next. }\end{array}$ & Q20 & $\begin{array}{l}\text { Nurses support patients in order to fulfill patients' hopes and desires. (Personal } \\
\text { knowing) }\end{array}$ \\
\hline \multirow[t]{3}{*}{15} & \multirow{3}{*}{$\begin{array}{l}\text { Nurses need to practice nursing within a caring perspective in their assessment } \\
\text { and interpretation of health care data. }\end{array}$} & Q4 & Nurses use knowledge of anatomy and physiology. (Empirical knowing) \\
\hline & & Q5 & Nurses use knowledge of latest clinical pharmacology. (Empirical knowing) \\
\hline & & Q6 & $\begin{array}{l}\text { Nurses use knowledge of well-versed in the state-of-the-art of medical devices } \\
\text { in their department. (Empirical knowing) }\end{array}$ \\
\hline 16 & $\begin{array}{l}\text { Nurses need to value patients as knowledgeable about their own selves and } \\
\text { their care. }\end{array}$ & & \\
\hline 17 & Nurses relate with their patients to create a shared sense of safety and security. & & \\
\hline 18 & $\begin{array}{l}\text { Competent nurses execute and follow up on tasks and emotions and use } \\
\text { creativity in meeting/exceeding patient needs. }\end{array}$ & & \\
\hline \multirow[t]{5}{*}{19} & \multirow[t]{5}{*}{$\begin{array}{l}\text { Knowing patients involves respecting the person as whole and complete in } \\
\text { each moment. }\end{array}$} & Q8 & $\begin{array}{l}\text { It is important for nurses to know what patients are most hoping now. } \\
\text { (Personal knowing) }\end{array}$ \\
\hline & & Q9 & Nurses respect patients as unique individuals. (Personal knowing) \\
\hline & & Q12 & $\begin{array}{l}\text { Even if patients lose their physical functions, nurses caring them with an } \\
\text { unchanged attitude. }\end{array}$ \\
\hline & & Q13 & $\begin{array}{l}\text { Nurses attempt to communicate with unconscious patients for the purpose of } \\
\text { resuscitating them, intentionally. (Ethical knowing) }\end{array}$ \\
\hline & & Q14 & $\begin{array}{l}\text { Nurses are required to respect the privacy of unconscious patients. (Ethical } \\
\text { knowing) }\end{array}$ \\
\hline 20 & $\begin{array}{l}\text { The competent nurse anticipates patient needs while respecting all belief } \\
\text { systems and focusing on patient healing. }\end{array}$ & & \\
\hline \multirow[t]{3}{*}{21} & \multirow{3}{*}{$\begin{array}{l}\text { Caring in nursing occurs in shared situations of teaching and learning between } \\
\text { nurses, patients, and family members. }\end{array}$} & Q21 & Nurses practice like growing up as nurse. (Aesthetic knowing) \\
\hline & & Q22 & $\begin{array}{l}\text { It is important for nurses to convey patients what nurses learned from nursing } \\
\text { and to share with their patients. (Aesthetic knowing) }\end{array}$ \\
\hline & & Q23 & $\begin{array}{l}\text { Nurses communicate their learned experiences of caring for patients with their } \\
\text { colleagues and nursing students, and share with them. (Aesthetic knowing) }\end{array}$ \\
\hline 22 & $\begin{array}{l}\text { Caring in nursing serves to reduce vulnerability and other stresses/anxiety } \\
\text { inherent in nurse-patient relationships. }\end{array}$ & & \\
\hline 23 & Selfless commitment to patients' needs, hopes, and dreams is caring. & & \\
\hline 24 & $\begin{array}{l}\text { As an expression of caring in nursing, technological competence is using many } \\
\text { ways of knowing so that the nurse and the patient can know each other. }\end{array}$ & & \\
\hline 25 & $\begin{array}{l}\text { Nurses use technology and human touch together in order to relate to their } \\
\text { patients with true presence and caring intentions. }\end{array}$ & & \\
\hline
\end{tabular}

Table 1. Comparison between the 25 items of TCCNI and 23 items of PITCCN.

TCCNI: Technological Competency Caring in Nursing Instrument, PITCCN: Perceived Inventory of Technological competency of caring in nursing. The Q12, Q13, Q14, Q15, and Q22 were in Inverted scale in the PITCCN. Negatively worded items had inverted values. 
Citation: Miyamoto M, Miyagawa M, Tanioka T, Yasuhara Y, Locsin R, et al. (2017) Comparative Examination between the Perceived Inventory of Technological Competency as Caring in Nursing (PITCCN) and the Technological Competency as Caring in Nursing Instrument (TCCNI). Int J Nurs Clin Pract 4: 267. doi: https://doi.org/10.15344/2394-4978/2017/267

Page 4 of 5

\begin{tabular}{|l|l|}
\hline Q3 & $\begin{array}{l}\text { Nurses share patient information acquired from technology } \\
\text { to illustrate team medical care, effectively. (Empirical } \\
\text { knowing) }\end{array}$ \\
\hline Q16 & $\begin{array}{l}\text { Nurses care for patients considering time and situation. } \\
\text { (Ethical knowing) }\end{array}$ \\
\hline Q17 & $\begin{array}{l}\text { Nurses provide the best nursing care for patients. (Ethical } \\
\text { knowing) }\end{array}$ \\
\hline Q19 & $\begin{array}{l}\text { Nurses continue to consider better care by reflecting on their } \\
\text { process of care. (Aesthetic knowing) }\end{array}$ \\
Table 2: Items which different in the TCCNI and the PITCCN. \\
TCCNI: Technological Competency Caring in Nursing Instrument, \\
PITCCN: Perceived Inventory of Technological competency of caring \\
in nursing.
\end{tabular}

Many patients who have lost part of their physical functions and those who are unconscious are admitted into ICUs in which the PITCCN is the target instrument for measurement. This is the very reason for preparing the content of PITCCN so that it can confirm whether or not the patients understood persons as irreducible and unpredictable and whether or not their dignity is protected and ethically appreciated. Also, in the TCCNI question numbers. 2, 7, 11 , it seemed that these questionsalso corresponded with the contents of PITCCN Q 1, 2, 7, and 10.

However, in the TCCNI, there is a question of "Knowing the "what" and "who" about a patient", that means to appreciate the patient as more than his/her physical condition," which suggests that patients should not be regarded as objects but as human beings. In realizing this goal, it is important that technology is administered competently clarifying the nurse's intention to care, leading to the understanding of persons as continuously and dynamically changing beings.

Locsin $[20,21]$ further describes that nurses can understand patients by using technologies proficiently. There is a similarity in the contents of certain questions such as "assessing the present state of patients and continuously understanding the state of patients based upon the information obtained from technology," "holistically understand patients" and "empathize with what a patient is experiencing now." Moreover, the commonalities between TCCNI and PITCCN included the understanding of patients using information obtained through technologies in what Locsin $[20,21]$ has called technological encounter.

Nurses therefore must fully utilize not only the empirical knowledge obtained from technology and nurse them appropriately. In order to realize this, aesthetics, ethics, and personal knowing must be in simultaneous recognition as critical to knowing persons as caring persons. Nurses can share the experience of receiving medical treatments and nursing care with patients leading to a more holistic understanding of patients.

The TCCNI question item numbers $(4,8,10,11,12,14-18,20$ and 25 as shown in Table 1) are items which views the nurse as the subject. Therefore, it is possible to measure the practice situation based on the nurse's TCCN. Meanwhile, if a change of the subject in the question sentence is made, wherein question item numbers $(1,2,3,5,6,7,11$, $19,21,22$ and 24) can measure the practical situation based on the nurse's TCCN.
The four items/factors with the PITCCN whichare different from those of the TCCNI, as shown in Table 2 are the actions for nurses to intentionally and continuously understand the patients and their family who are the recipients of care. These actions are the very practice of caring in nursing, and the nurses' actions to provide highquality care is evident in their expressions technological competency as caring in nursing. Items in the TCCNI that did not match with those of PITCCN were those created based on the TCCNI's theoretical hypothesis of "nursing is a science and a professional practice." It was clear that the PITCCN is aimed at measuring technological competency as caring in practice.

As a limitation of the instruments, a ceiling effect was observed. In order to solve this problem, the question format of asking practical situation was considereduseful rather than questions as a form of the ideal image of nursing as caring.

\section{Conclusions}

The nurse and persons being nursed altogether are known as participants in their care instead of as objects who need to be known. Different aspects of knowing persons as caring invoke pertinent actions thereby providing high-quality nursing care. It is deliberated that useful data supporting high quality practice with technologies providing high quality nursing is best declared through theorybased practice such those grounded in the middle-range theory of TCCN. This was well clarified using the PITCCN of Japan. This comparative research study provided support for implications on the utilization and transformation of education and research, from theory to practice utilizing continuing professional education and formal academic education fostering the demand for human caring in highly technological nursing care environments.

The future engagement of nursing in the technological world can be evaluated from the perspective of the nurse and the persons being nursed. Ultimately, findings of this conjoint nurse-focused and patient-focused instrument will be to deliver guiding propositions through continuing professional education. The PITCCN and the TCCNI together lead the way towards quality improvement of nursing and its practice.

\section{Competing Interests}

The author declears that they have no competing interest exists.

\section{Funding}

This work was supported by JSPS KAKENHI Grant, Number JP15K15798 and JP17K1215900.

\section{References}

1. Mayeroff M (1990) On Caring, New York: William Morrow Paperbacks, USA, $144 \mathrm{p}$.

2. Blasdell ND (2017) The Meaning of Caring in Nursing Practice. Int J Nurs Clin Pract 4: 238.

3. Leininger M (2008) Overview of Leininger's Theory of Culture Care Diversity and Universality.

4. Leininger MM, McFarland MR (2006) Culture care diversity and universality: A worldwide nursing theory (2nd ed.), Sudbury, MA: Jones and Bartlett, USA, $413 \mathrm{p}$.

5. Sato $Y$, Inoue K, Niino M, Kamata M, Kobayashi M, Fujisawa Y, Yamoto $Y$ (2004) Study on the concept of caring in nursing: Content analysis for Japanese nursing studies on caring. Yamagata journal of Health Science 7: $41-48$. 
Citation: Miyamoto M, Miyagawa M, Tanioka T, Yasuhara Y, Locsin R, et al. (2017) Comparative Examination between the Perceived Inventory of Technological Competency as Caring in Nursing (PITCCN) and the Technological Competency as Caring in Nursing Instrument (TCCNI). Int J Nurs Clin Pract 4: 267. doi: https://doi.org/10.15344/2394-4978/2017/267

6. Sato $S(2010)$ What is Caring on Nursing. Journal of Niigata Seiryo Academic Society 3: 11-20. Miyawaki M (2011) Measurement instruments on caring in nursing. The Japanese journal of nursing research 44: 159171.

7. Miyawaki M (2011) Measurement instruments on caring in nursing. The Japanese journal of nursing research 44: 159-171.

8. Katsuhara Y (2013) Challenge for Making Nursing Visible. The Journal of Japan Academy of Nursing Administration and Policies 17: 109-115.

9. Watson $\mathrm{J}$ (2001) Assessing and Measuring Caring in Nursing and Health Sciences, New York, Springer Publishing Company, USA, 368 p.

10. Larson PJ (1984) Important nurse caring behaviors perceived by patients with cancer. Oncol Nurs Forum 11: 46-50.

11. Wolf ZR (1986) The caring concept and nurse identified caring behaviors. Top Clin Nurs 8: 84-93.

12. Locsin RC (1999) Development of an instrument to measure technological caring in nursing. Nursing and Health Sciences 1: 27-34.

13. Parcells DA, Locsin RC (2011) Development and psychometric testing of the technological competence as caring in nursing instrument. International Journal for Human Caring 15: 8-13.

14. Biswas RS, Kongsuwan R, Matchim Y (2016) Technological Competency as Caring in Nursing as Perceived by ICU Nurses in Bangladesh and Its Related Factors. Songklanagarind Journal of Nursing 36: 1-20.

15. Kato K, Tanioka T, Yasuhara $Y$, et al. (2017) The Development of the Perceived Inventory of Technological Competency as Caring in Nursing. Shikoku Acta Medica 73: 151-160.

16. NOTE, TCCNI has already been translated into Japanese by Tanioka, but it is not yet published in academic Journal.

17. Locsin R (2005) Technological Competency as Caring in Nursing: A Model for Practice, Indianapolis: Sigma Theta Tau International Press, USA, 229

18. Carper BA (1978) Fundamental Patterns of Knowing in Nursing. Advances in Nursing Science 1: 13-24.

19. Boykin A, Schoenhofer SO (2001) Nursing as caring: A model for transforming practice, Boston: Jones and Bartlett Learning, USA, $71 \mathrm{p}$

20. Locsin R (2016) The theory of Technological Competency as Caring in Nursing: Guiding nursing and health care. Shikoku Acta Medica 72 : 163170

21. Locsin R (2017) The co-existence of technology and Caring in nursing in the Theory of Technological Competency as Caring in Nursing. J Med Invest 64: 160-164. 